\title{
UNMANNED AERIAL VEHICLE IN CADASTRAL APPLICATIONS
}

\author{
M. Manyoky ${ }^{\mathrm{a}}$, P. Theiler ${ }^{\mathrm{a}}$, D. Steudler ${ }^{\mathrm{b}}$, H. Eisenbeiss ${ }^{\mathrm{a}}{ }^{*}$ \\ ${ }^{a}$ Institute of Geodesy and Photogrammetry, ETH Zurich, 8093 Zurich, Switzerland - (henri.eisenbeiss, \\ pascal.theiler)@geod.baug.ethz.ch, manyoky@nsl.ethz.ch \\ ${ }^{\mathrm{b}}$ Swiss Federal Office of Topography swisstopo, Federal Directorate for Cadastral Surveying, 3084 Wabern, \\ Switzerland, Daniel.Steudler@swisstopo.ch
}

Commission I, WG I/V

KEY WORDS: UAVs, Surveying, Measurement, Mapping, Planning, Modelling, High Resolution, Sustainable

\begin{abstract}
:
This paper presents the investigation of UAVs (Unmanned Aerial Vehicles) for use in cadastral surveying. Within the scope of a pilot study UAVs were tested for capturing geodata and compared with conventional data acquisition methods for cadastral surveying. Two study sites were therefore surveyed with a tachymeter-GNSS combination as well as a UAV system. The workflows of both methods were investigated and the resulting data were compared with the requirements of Swiss cadastral surveying.

Concerning data acquisition and evaluation, the two systems are found to be comparable in terms of time expenditure, accuracy, and completeness. In conclusion, the UAV image orientation proved to be the limiting factor for the obtained accuracy due to the lowcost camera including camera calibration, image quality, and definition of the ground control points (natural or artificial). However, the required level of accuracy for cadastral surveying was reached. The advantage of UAV systems lies in their high flexibility and efficiency in capturing the surface of an area from a low flight altitude. In addition, further information such as orthoimages, elevation models and 3D objects can easily be gained from UAV images. Altogether, this project endorses the benefit of using UAVs in cadastral applications and the new opportunities they provide for cadastral surveying.
\end{abstract}

\section{INTRODUCTION}

Due to the growing interest in updating geodata - mainly 3D data and cadastral data as basis for GIS and mapping applications - there is a demand for a fast and efficient surveying method that combines data acquisition with additional information such as images, orthoimages, 3D-models of buildings and infrastructure, and elevation models. One possibility for such a fast and efficient capture of georeferenced data is the use of UAV systems (Unmanned Aerial Vehicles).

In cadastral applications tachymeters and GNSS receivers (Global Navigation Satellite System) are usually used. These instruments exhibit a high level of accuracy and performance in surveying object points and lines. In contrast to these traditional surveying methods, photogrammetric applications are used to create and update maps or orthoimages, especially for larger areas. Conventional airborne images, however, are limited in their use for cadastral surveying, mainly because of the high flight altitude, the resulting image resolution and the high expenses.

The rapid development of robotic systems over the last few years allowed for the use of unmanned aerial vehicles as a photogrammetric data acquisition platform. These autonomously flying UAV systems are usually equipped with different sensors for navigation, positioning, and mapping such as still-video cameras, LiDAR systems and others (Manyoky et al. 2011).

In this pilot study the traditional cadastral surveying method using tachymetry/GNSS is compared to the novel surveying method using UAV systems.

\section{DATA AQUISITION}

\subsection{Test Areas}

In order to compare the two different methods they were applied in two test areas that represent typical mapping tasks. The first test area is located in Krattigen, in the country side of the Canton of Bern. This site is a typical parcel in a mountainous area in Switzerland. The second test area is located at the Campus Science City (Hoenggerberg) ETH Zurich, representing a typical suburban area (see Figure 1).
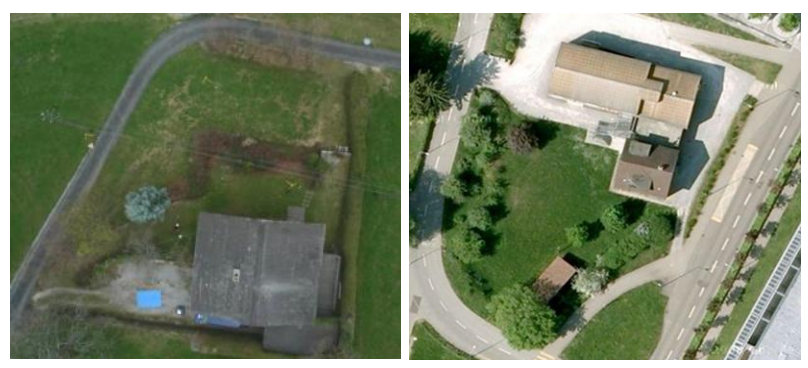

Figure 1. Left: Overview image of the test area Krattigen/BE, Right: Image with the test site Campus Science City ETH Hoenggerberg/ZH. Both images were taken from a camera mounted on a UAV

\subsection{Used Methods}

The two test sites were surveyed with the two surveying methods, tachymetry/GNSS and UAV.

\footnotetext{
* Corresponding author.
} 
Tachymetry/GNSS measurements were performed according to cadastral surveying standards. For data acquisition reference points were measured by GNSS in the field from which further field and object points were captured by tachymeter. This includes the measurement of surface or object points that are relevant for cadastral surveying. The measurement of reference point with GNSS is standard practice in Swiss official cadastral surveying as long as the required accuracy based on the technical requirements of the Swiss official cadastral surveying (TVAV - Technische Verordnung über die Amtliche Vermessung) can be achieved.

The UAV method for the acquisition of geodata is based on good and appropriate flight planning. In Figure 2 the flight planning for the test area Campus Science City ETH Zurich is shown, using the provided software of the UAV manufacturer.

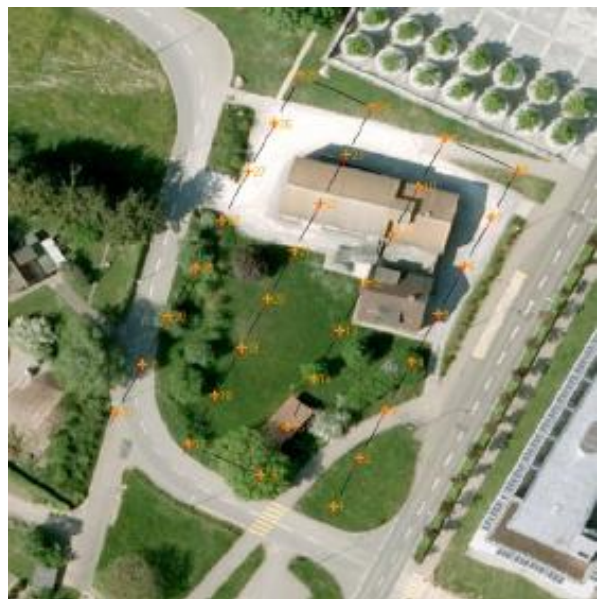

Figure 2. Flight planning of the test area Campus Science City ETH Hoenggerberg

With the help of these flight plans the UAV is steered autonomously over predefined routes. Along these paths aerial images are taken. In a second turn the camera on the UAV was tilted and the UAV was navigated in the assisted flight mode around the building complexes to acquire images from the facades of the buildings. In order to transform the acquired data to the national coordinate reference system control points from the Swiss official cadastral surveying are required. These control points are marked with field targets that need to be visible in the UAV images.

In both test areas the parcels, the corners of the buildings and the surrounding vegetation were captured by tachymetry/GNSS and observed by the camera mounted on the UAV.

\subsection{Used Systems for the Tachymetry/GNSS Method}

The highest possible accuracy for the tachymetry/GNSS method depends on the applied instruments. For our pilot study the two instruments listed in Table 1 were used for data acquisition in the field.

\begin{tabular}{|c|c|c|}
\hline Instrument & \multicolumn{2}{|c|}{ Accuracy } \\
\hline Leica TPS System 1200 & $\begin{array}{c}\text { Orientation } \\
0.3 \text { mgon }\end{array}$ & $\begin{array}{c}\text { Distance } \\
2 \mathrm{~mm}+2 \mathrm{ppm}\end{array}$ \\
\hline Leica GPS System 1200 & 3D Coordina & Quality $2-3 \mathrm{~cm}$ \\
\hline
\end{tabular}

Table 1. Specifications of the surveying systems, tachymetry/GNSS method

\subsection{Used Systems for the UAV Method}

The used flight system is the Falcon 8 of Ascending Technologies (AscTec). This octocopter features eight rotors, which guarantee good flight stability at wind speeds of up to 10 $\mathrm{m} / \mathrm{sec}$. Flight times of up to $20 \mathrm{~min}$ with a payload capacity of $500 \mathrm{~g}$ are possible. The maximum takeoff weight should not exceed $1.8 \mathrm{~kg}$. For position determination, the octocopter is equipped with a GNSS, a barometric height sensor, a compass and an inertial measurement unit (IMU).

While flying on the path that has been defined during the flight planning, the device can hold its own position via GPS (Global Positioning System) information. If necessary, however, the position of the UAV can be changed with a remote control. In addition, the pilot can also take additional images.
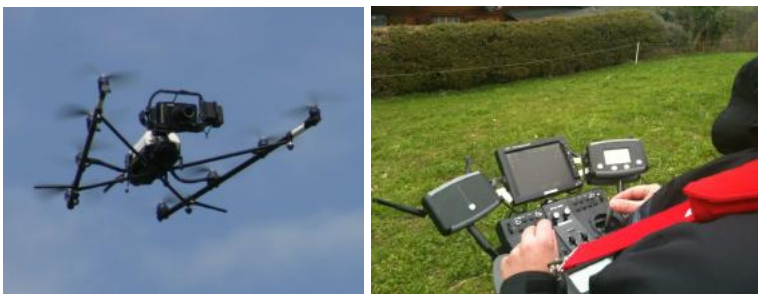

Figure 3. Used UAV system: Octocopter Falcon 8, AscTec

The camera can be tilted to any angle along the vertical and horizontal axis. With the provided flight planning software of AscTec, flight missions are planned for autonomous flights. The Falcon 8 has a V-shaped form, which allows an unrestricted field of view for the camera. This octocopter is therefore suitable for aerial photography, inspection and documentation from the air. Figure 3 shows the octocopter during the data acquisition (left) and the remote control with a monitor showing the current camera image/video stream (right). The transmission time for live view is instantaneous. However, the images are stored on the flash-card of the camera mounted on the UAV.

For image acquisition a Panasonic Lumix DMC-LX3 camera is mounted on the Falcon 8. This camera offers a multi-format sensor in three formats (4:3, 3:2 and 16:9), which leads to a 10 mega pixel resolution. The Panasonic LX3 has a small zoom range of $24 \mathrm{~mm}$. It supports RAW formats as well as manual settings. The camera specifications are listed in Table 2.

\begin{tabular}{|l|l|}
\hline \multicolumn{2}{|l|}{ Camera Specifications } \\
\hline $\begin{array}{l}\text { Focal length: } \\
\text { Luminous intensity: }\end{array}$ & $\begin{array}{l}\text { 5.1-12.8mm }(35 \mathrm{~mm} \text { Equiv.: } 24-60 \mathrm{~mm}) \\
\text { WW: F2.0 }-8.0 \\
\text { Tele: F2.8-8.0 }\end{array}$ \\
Shutter lag incl. & $0.63-0.71 \mathrm{~s}$ \\
autofocus: & 2.0um $(1 / 1.63 ")$ \\
Sensor size: & 265g incl. battery \\
Weight: & \\
\hline
\end{tabular}

Table 2. Camera specifications, Panasonic Lumix DMC-LX3

\section{RESULTS}

All individual steps of the workflow were completed for both study areas using tachymetry/GNSS and UAV. This workflow encompassed data acquisition, processing, evaluation (with data cleansing), as well as map design. 


\subsection{Tachymeter Data Evaluation}

The data evaluation of the tachymetry/GNSS method was carried out according to the Swiss official cadastral surveying standards. After rectification and transformation of the acquired data, tachymetry and GNSS data were merged and displayed on a map. Such a map design was carried out for both test areas, Krattigen and Campus Science City ETH Zurich.

After data cleansing and classification of the measured points, the data can be used for generating or updating cadastral maps. To verify the resulting dataset of the tachymetry method, the measurements of various points such as parcel boundary lines or main road points were compared to the general site plan from Swiss official cadastral surveying. In Figure 4 the site plan of the Krattigen test area is shown, overlaid with the acquired tachymetric and GNSS data.

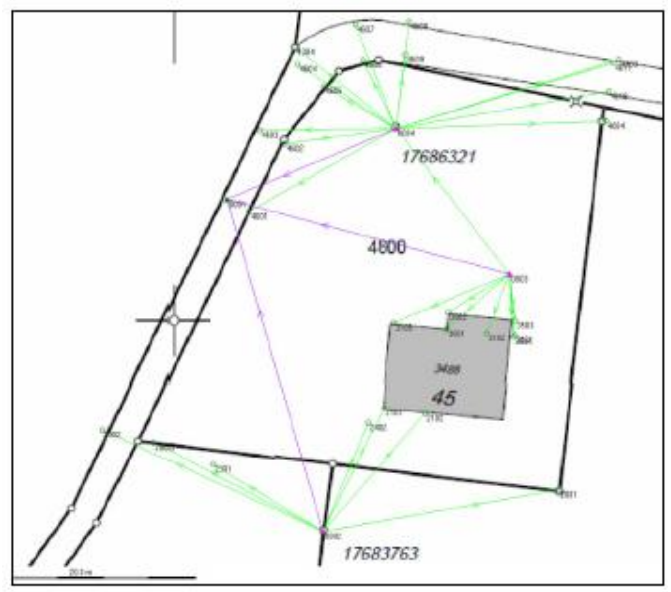

Figure 4. Site map from the Swiss official cadastral surveying including the achieved measurements using tachymetry/GNSS (test site Krattigen)

Figure 4 shows four reference points measured with GNSS serving as basis for the major street points and building edges measured by tachymeter.

Finally, all classified points were included in the Software CAPLAN where the points are displayed based on the previously defined classification code to create a map of the surveyed area. In Figure 5 the map of the area Science City Campus ETH Zurich that has been generated in CAPLAN is shown. The elevation model in orange was calculated using the height information from the tachymeter and GNSS measurements of the surveyed field points. Additional field points like drains, masts or single trees are displayed in the map as well.

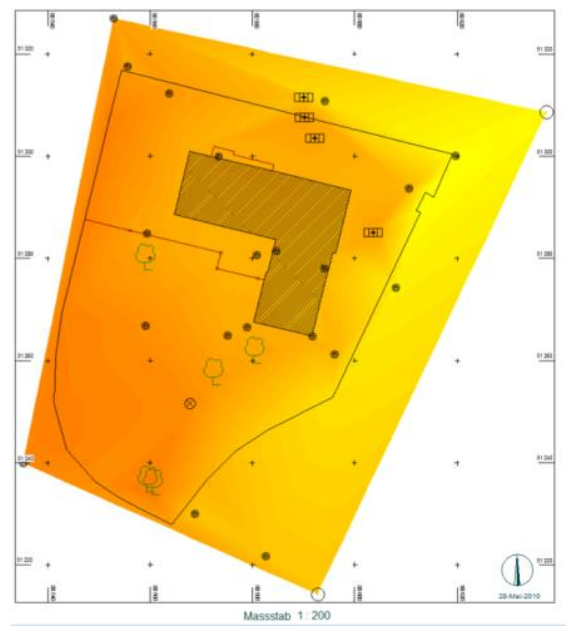

Figure 5. Resulting map in CAPLAN using tachymetry and GNSS information of the Campus Science City ETH Zurich

\subsection{UAV Data Evaluation}

The evaluation of the UAV data requires the camera calibration. The camera calibration was done with iWitness. This calibration method uses color-coded targets which are placed on the ground. The camera calibration coefficients are then calculated by detecting the targets and performing a self-calibration procedure. This is done via bundle adjustment where the additional parameters are being adjusted.

Further UAV data processing steps comprise the image orientation and the semi-automatic measurement of object structures and geometries in stereo images

Similar to the workflow of the combined tachymetry/GNSS method, the surveyed field points have to be classified in order to generate a map. The coded points were imported into ArcGIS 9.3 (ESRI) and a map of both data sets was finalized. In the map different vegetation types, buildings and streets as well as additional field points were differentiated and modeled based on the information of the stereoscopic measurements.

Figure 6 illustrates the generated maps for the Campus Science City ETH Zurich and Figure 7 the one of the Krattigen test area. 


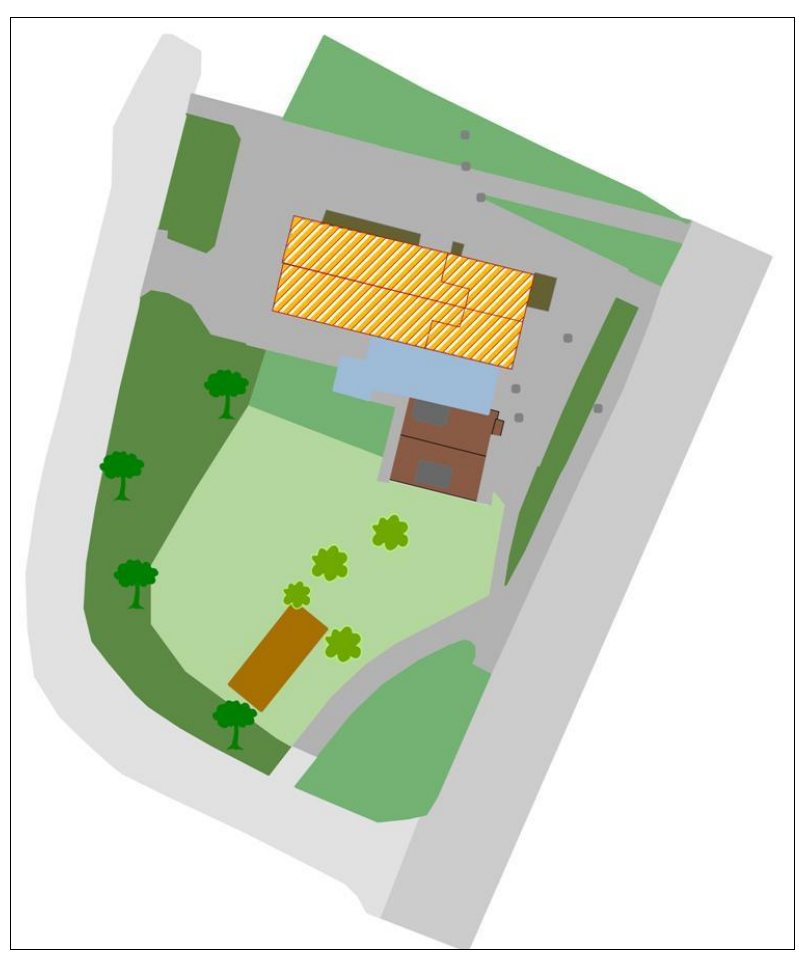

Figure 6. Map of the Science City ETH Zurich test area generated from UAV images

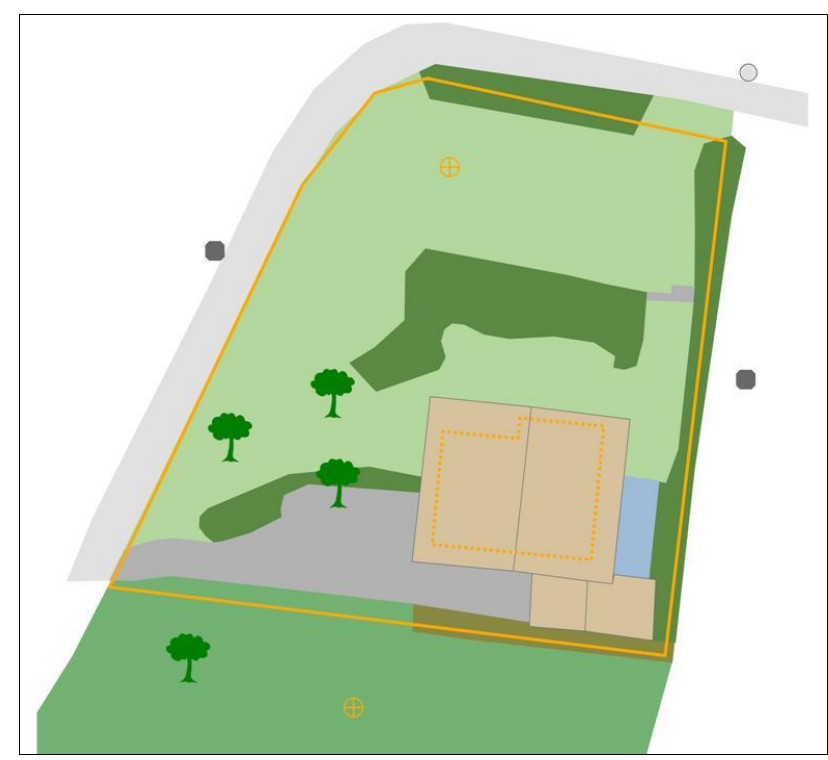

Figure 7. Map of the Krattigen test area generated from UAV images

\section{DISCUSSION}

\subsection{Comparison of the Two Surveying Methods}

Both methods, tachymetry/GNSS and UAV, deliver comparable results with respect to data acquisition, processing and evaluation, and expenditure of time. While with the tachymetry method only the surveyed points in field can be mapped, the UAV method can result in a much more detailed map, depending on the preferred level of detail and the investment in time. However, if further information of the area like land use or vegetation has to be documented in the map, the UAV method is much more efficient due to the additional points which can be measured very fast without any new survey, even in a post-processing step.

\subsection{Cadastral Restrictions in Switzerland}

For the verification of the correctness of the measurements and usability of UAV data in cadastral applications, the achieved results were compared to the accuracy standards of the cadastral survey. In Switzerland, the required accuracy for cadastral surveying is defined in the technical ordinances on official cadastral surveying (VAV, 2008; TVAV, 2008).

In Swiss cadastral surveying, the territory is divided up into 5 zones with different levels of surveying tolerances, specified in article 3 of the TVAV:

\section{TS1: Central business districts}

TS2: Built-up areas and construction zones

TS3: Intensively used agricultural and forested areas

TS4: Extensively used agricultural and forested areas TS5: Alpine and non-productive areas

The accuracies for points (e.g. building points, boundary points, land cover) for the different tolerance levels are listed in TVAV articles 27-32. The selected study areas lie in the TS2 (Campus Science City ETH Zurich) and in the TS3 (Krattigen).

\begin{tabular}{|l|cc|}
\hline Accuracies & \multicolumn{2}{|c|}{ Zones } \\
\hline & TS2 & TS3 \\
Lateral accuracy & & \\
Land cover and single objects & $10 \mathrm{~cm}$ & $20 \mathrm{~cm}$ \\
Land ownership & $3.5 \mathrm{~cm}$ & $7 \mathrm{~cm}$ \\
Not exactly defined point & $20 \mathrm{~cm}$ & $35 \mathrm{~cm}$ \\
Height accuracy & & \\
Height (DTM 2m Grid) & $80 \mathrm{~cm}$ & $80 \mathrm{~cm}$ \\
Not exactly defined terrains & $200 \mathrm{~cm}$ & $200 \mathrm{~cm}$ \\
\hline
\end{tabular}

Table 3. Standard deviation for the zones TS2 and TS3 of the Swiss TVAV

In Table 3 the required lateral and vertical accuracies of given information layers relevant for this pilot study are listed.

\subsection{Achieved Accuracy}

The achieved accuracy using the tachymetry/GNSS method depends on the instruments. Comparing the used systems, tachymetry is able to measure in millimeters while GNSS measurements have a $3 \mathrm{D}$ coordinate quality of $2-3 \mathrm{~cm}$. The possible accuracy of GNSS data can be increased using additional information of data from a reference station. The net adjustment of the Campus Science City ETH Zurich (TS2) showed confidence ellipses of up to $0.5 \mathrm{~cm}$. For the Krattigen area (TS3), the difference between the official coordinates and the measured points is about $2.5 \mathrm{~cm}$, whereas the official cadastral surveying point itself has an accuracy of $3.8 \mathrm{~cm}$.

The UAV method reveals the need for good image orientation as the accuracy of UAV systems is limited by the camera calibration, the image quality and the definition of the ground control points (natural or artificial).

During the flight no noise reduction in the actual imagery (built-in noise-reduction of the camera) was conducted and the 
built-in stabilization was deactivated because it delivers worse imagery.

However, the recognizable motion blur in the images affects the image orientation. Due to these distortions the laid-out targets cannot be detected accurately in the images, causing difficulties to manually measure the center of these points.

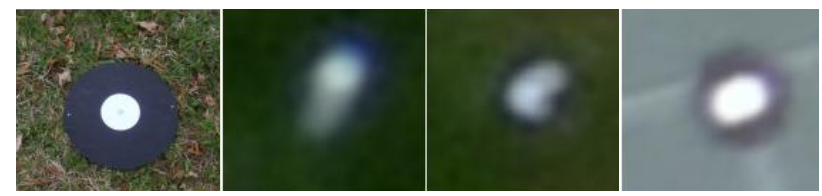

Figure 8. The original target (left) and the corresponding targets in the image with motion blur

The targets shown in Figure 8 could not be used as tie points for the bundle block adjustment in the data evaluations because their center could not be defined accurately enough. A possible solution to measure these targets would be the application of a centroid operator (see Figure 9). The centroid operator determines the central point of distorted targets in images. However, due to the white trail of the blurred images, even the centroid operator could not determine the center of all targets.

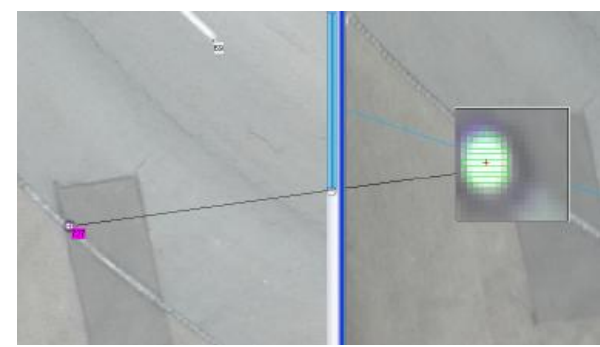

Figure 9. Determination of the target centre points using the centroid operator

The required size of the targets in the field depends on the planned flight altitude and the focal length of the camera.

The images shown in Figure 10 were taken from a height of about $40 \mathrm{~m}$ above ground. At such low altitudes no targets are needed as long as clearly defined terrain vertices are visible in the area.

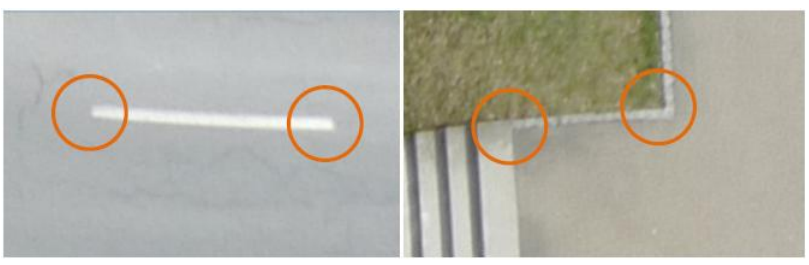

Figure 10. Road marking and curb edges, which can be used as natural control points (highlighted with orange circles)

These clearly visible terrain points can be used as control points if they are measured in the field with real-time kinematic GNSS.

The Swiss TVAV requires lateral positional accuracy for the information levels „land cover" and „single objects“ of $10 \mathrm{~cm}$ (TS2) or 20cm (TS3) as shown in Table 3. In this pilot project, an average accuracy of $2.3 \mathrm{~cm}$ (lateral) and $3.8 \mathrm{~cm}$ (vertical) could be reached using UAV images.

These accuracies meet the demands of the technical ordinances. Therefore, UAV methods are viable options for the efficient measurement of ground covers and individual objects such as buildings, roads, paths, sidewalks, fields, gardens, water or forest edges etc.

The average deviations of the lateral position compared to the reference points from the Swiss official cadastral surveying of the information layer ,properties" and „territorial boundaries" are on average only $1.8 \mathrm{~cm}$ lateral and $3.5 \mathrm{~cm}$ vertical within the test area Campus Science City ETH Zurich. In Krattigen, accuracies of $2.0 \mathrm{~cm}$ lateral and $5.0 \mathrm{~cm}$ vertical could be reached. Again, these values are below the required accuracy of $3.5 \mathrm{~cm}$ lateral and $7 \mathrm{~cm}$ vertical (TS2) (compare Table 3).

\subsection{Additional Benefit of Using UAV Data}

Compared to GNSS or tachymetric measurements, the UAV method allows for the derivation of much more information. Based on the image orientation, a digital elevation model of different grid and area sizes can be calculated. In addition, 3D models of objects such as buildings can be generated based on the captured UAV data. Figure 11 shows a 3D model of the building HXE on the Campus Science City ETH Zurich, derived from UAV data. This model was created by Ober (2010) in a project work about the orientation and combination of image data using the octocopter Falcon 8.

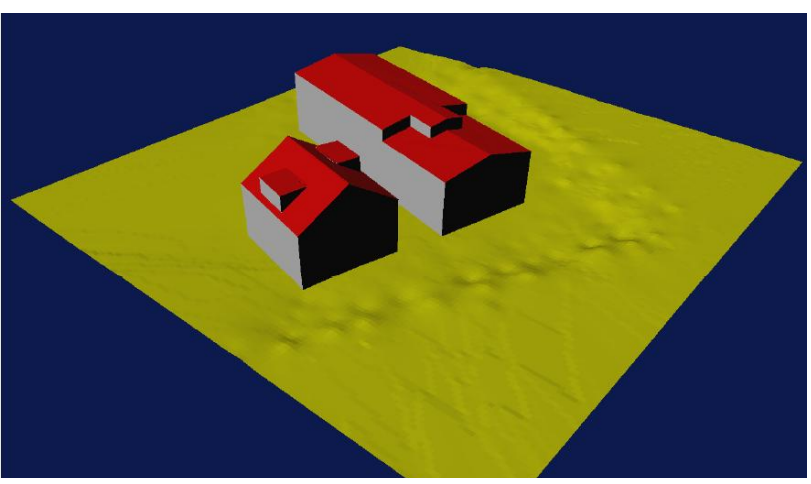

Figure 11. Non/textured 3D-Model derived from UAV images of the HXE-building at Campus Science City ETH Zurich

Objects such as roofs, streets or areas of vegetation can be measured and classified with the help of photogrammetric evaluation software such as LPS Stereo Analyst. In order to allow for better visualization, these data were exported to PhotoModeler. In addition, this software allows for applying a complete texture to all objects as long as images from the roof and the façade are available.

Figure 12 shows the texture components and the modeled HXE building at Campus Science City ETH Hoenggerberg. 

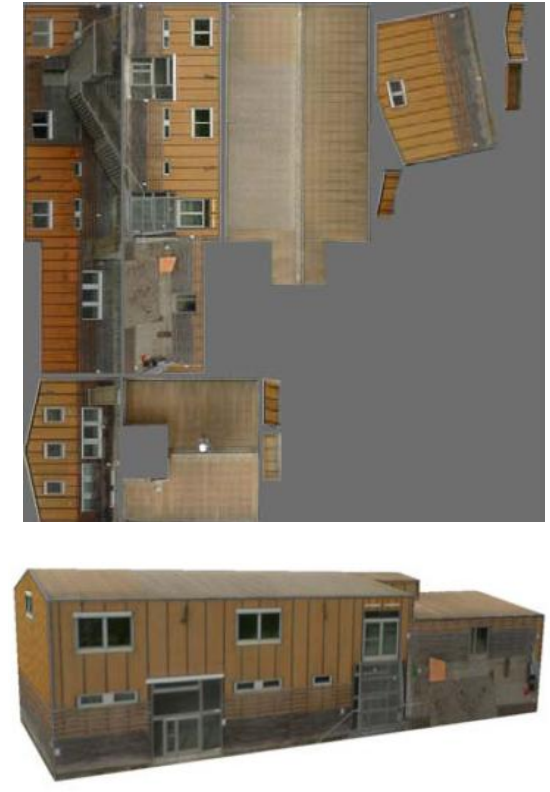

Figure 12. Texture components and the 3D-Model derived from UAV images of the HXE-building at Campus Science City Campus ETH Hoenggerberg, displayed in VRMLVIEW

The final textured model can be exported as VRML (Virtual Reality Modeling Language) for general 3D viewers or as a KMZ file for display in Google Earth, see Figure 13.

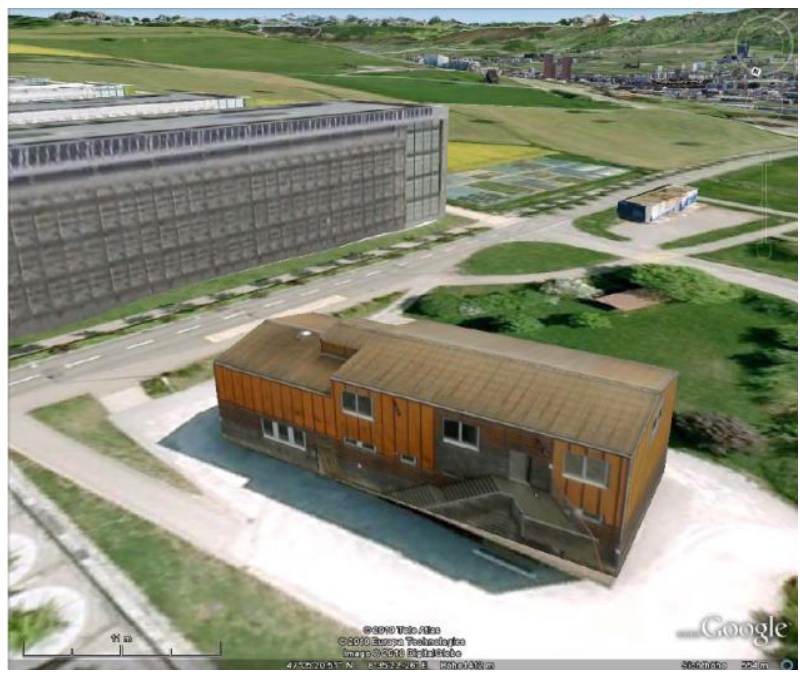

Figure 13. 3D-Model derived from UAV images of the HXEbuilding at Campus Science City ETH Hoenggerberg, imported to Google Earth

\section{CONCLUSION}

Both methods, tachymetry/GNSS and UAV, were confirmed to be comparable in terms of accuracy, completeness and expenditure of time.

The advantage of UAV systems is the ability to quickly observe the surface of areas at low flying altitude while still meeting the accuracy requirements of Swiss cadastral surveying.

As our results show, the limiting factors for image orientation accuracy are the camera calibration, the image quality, and the definition of the ground control points in the image space.
The application of UAV systems for cadastral surveying is appropriate for the capturing of land cover or single objects. If the area is already documented in official cadastral surveying, further information can efficiently be gained even in a postprocessing step. Therefore, UAV systems proved suitable to be used in addition to the standard surveying methods in order to gain further data through the acquired images such as overview images or orthoimages. Moreover, another added value of using UAVs in cadastral applications is the effortless generation of elevation models and 3D objects.

\section{OUTLOOK}

The UAV method with appropriate photogrammetric evaluation methods offers a great potential to gain information from the captured data that are useful for cadastral applications. These derivates from UAV measurements can present a great additional benefit to users of cadastral data, such as real estate agencies and insurance companies. In areas where access can be difficult, e.g. after natural calamities or in 3rd world countries, UAVs offer a valuable alternative to tachymetry and GNSS. With further developments of specific system technology, the usability of UAV systems will increase in cadastral surveying.

In order to decrease the complexity of data processing the development of an efficient workflow for data analysis of the aerial images is needed. This includes appropriate software packages as well as reliable automation of image orientation and geometry measurement. This way time effort and business profitability can be improved.

In the future, UAVs will be used where a need of high accuracy is required and fast data capturing is demanded. Therefore, the use of UAVs is an opportunity for cadastral surveying.

\section{ACKNOWLEDGEMENTS}

We thank Christoph Ober and David Novák for their contribution to this work.

\section{REFERENCES}

\section{References from Journals:}

Manyoky, M., Theiler, P., Steudler, D. and Eisenbeiss, H., 2011. Anwendung von UAV's in der Katastervermessung, cadastre, 5 (April 2011), pp. 16-17.

\section{References from Other Literature:}

Ober, C., 2010. Orientierung und Kombination von Bilddaten am Beispiel des Oktokopters Falcon 8, Masterprojektarbeit 2010, ETH Zürich, pp. 40-44.

TVAV, 2008, Das Eidgenössische Departement für Verteidigung, Bevölkerungsschutz und Sport, Technische Verordnung des VBS über die amtliche Vermessung, 10. Juni 1994 (Stand 1. Juli 2008), pp. 2-16.

VAV, 2008, Der Schweizerische Bundesrat, Verordnung über die amtliche Vermessung, 18. November 1992 (Stand 1. Juli 2008), pp. 2-3. 